\title{
Atenção À Saúde da Criança no Estado de São Paulo
}

\author{
Sanine, Patricia Rodrigues; Pinho, Valdemar Pereira de; Castanheira, Elen Rose \\ Lodeiro
}

Faculdade de Medicina de Botucatu - Fmb|Unesp - patsanine@yahoo.com.br

INTRODUÇÃO: o estado de São Paulo representa 43\% da população brasileira. em 2010, o estado era composto por 5.538 .945 crianças menores de 10 anos. As ações de saúde da criança na Atenção Primária à Saúde - APS estão entre as mais tradicionais e bem estruturadas no estado, no entanto, persistem elevadas taxas de mortalidade infantil e agravos evitáveis, como a ocorrência de sífilis congênita. OBJETIVO: Avaliar a organização da assistência prestada à saúde da criança nos diferentes tipos de serviços que compõe a rede de APS no estado de São Paulo. METODOLOGIA: Foi utilizado banco de dados do questionário QualiAB, aplicado no ano de 2010 como instrumento censitário, priorizando municípios com menos de 100 mil habitantes. As frequências das questões referentes ao atendimento infantil, incluindo atenção ao pré-natal, foram selecionadas e analisadas conforme o tipo de serviço (Unidade Saúde da Família - USF, Unidade Básica de Saúde "Tradicional" - UBS, Unidades Básicas com Agente Comunitário de Saúde ou Programa Saúde da Família - UBS/ACS/PSF, e outros). RESULTADOS: Responderam que atendem criança 2.687 serviços de APS localizados em 90,6\% dos municípios que compõe o estado. a avaliação permitiu observar que as atuais políticas públicas de atenção à saúde da criança, propostas nas linhas de cuidado, na agenda de compromissos para a saúde integral da criança e redução da mortalidade infantil e no Programa de Humanização no Prénatal e Nascimento - PHPN, apontam para o desenvolvimento de práticas que compreendem o "ser criança" como sujeito de direitos. a aplicação do QualiAB identificou na organização dos serviços que apesar da grande maioria de ações de saúde da criança ainda serem as práticas mais tradicionais, como a vacinação e orientações sobre aleitamento materno e desnutrição, os serviços caracterizados como USF são os que melhor representam os princípios de integralidade, apresentando maior diversidade de ações, além de abordar temas mais contemporâneos, como a violência, saúde do escolar e assistência odontológica para bebês. São também estes, os serviços que mais se aproximam da política de equidade, com maiores frequências em práticas como: delimitação de área de abrangência, descentralização, conhecimento da população atendida, além de maior facilidade no acesso. Chama atenção a proporção de serviços que não possuem gerência ou são gerenciados pela Secretaria de Saúde, o número elevado de serviços que não ofertam vacinação ou não aplicam medicamentos essenciais ao atendimento infantil, como a penicilina benzatina, além de falhas no segmento de protocolos, como no caso do pré-natal e no tratamento da sífilis. CONCLUSÃO: Apesar dos avanços apresentados, há necessidade de melhorias nas condições de saúde, especialmente quando comparado com os patamares alcançados em outros países, o que constitui-se num grande desafio ao sistema de saúde do estado.

Sanine, Patricia Rodrigues; Pinho, Valdemar Pereira de; Castanheira, Elen Rose Lodeiro. Atenção À Saúde da Criança no Estado de São Paulo.. In: Anais do Congresso Internacional de Humanidades \& Humanização em Saúde [= Blucher Medical Proceedings, num.2, vol.1]. São Paulo: Editora Blucher, 2014. ISSN 2357-7282 DOI 10.5151/medpro-cihhs-10438 